\title{
Altered expression of cellular proliferation, apoptosis and the cell cycle-related genes in lung cancer cells with acquired resistance to EGFR tyrosine kinase inhibitors
}

\author{
TAE-GUL LEE ${ }^{1 *}$, EUN-HUI JEONG ${ }^{1,2^{*}}$, IL JAE MIN $^{1}$, SEO YUN KIM ${ }^{1}$, \\ HYE-RYOUN KIM ${ }^{1}$ and CHEOL HYEON KIM ${ }^{1,2}$ \\ ${ }^{1}$ Division of Pulmonology, Department of Internal Medicine, Korea Cancer Center Hospital, \\ Seoul 139-706; ${ }^{2}$ University of Science and Technology (UST), Daejeon 305-350, Republic of Korea
}

Received September 21, 2015; Accepted March 3, 2017

DOI: $10.3892 / 01.2017 .6428$

\begin{abstract}
Non-small cell lung cancers harboring somatic gain-of-function mutations in the epidermal growth factor receptor (EGFR) tyrosine kinase domain respond well to treatment with EGFR tyrosine kinase inhibitors (TKIs) including gefitinib and erlotinib. However, all patients who experience a marked improvement with these drugs eventually develop disease progression due to the acquisition of drug resistance. Approximately half of the cases with acquired resistance to EGFR TKIs can be accounted for by a second-site mutation in exon 20 of the EGFR kinase domain (T790M). However, the changes of gene expression involved in EGFR TKI resistance due to the T790M mutation remain poorly defined. The present study established lung cancer cell lines that were resistant to gefitinib or erlotinib, and these cell lines were verified to contain the EGFR T790M mutation. The differential expression of genes associated with acquired resistance was verified in the present study by mRNA microarray analysis. Among the genes whose expression was significantly altered, genes whose expression was altered in gefitinib- and erlotinib-resistant cells were focused on. Notably, a total of 1,617 genes were identified as being differentially expressed in gefitinib- and erlotinib-resistant cells. Indeed, Gene ontology analysis revealed altered expression of genes involved in the regulation of cellular proliferation, apoptosis, and the cell cycle in EGFR TKI-resistant cells. The present results demonstrate distinctive gene expression patterns
\end{abstract}

Correspondence to: Dr Cheol Hyeon Kim, Division of Pulmonology, Department of Internal Medicine, Korea Cancer Center Hospital, 75 Nowon-Gil, Nowon-Gu, Seoul 139-706, Republic of Korea

E-mail: cheol@kcch.re.kr

*Contributed equally

Key words: epidermal growth factor receptor tyrosine kinase inhibitors, acquired resistance, lung cancer, mRNA microarray, T790M of EGFR TKI-resistant lung cancer cells with the EGFR T790M mutation. The present study can provide key insights into gene expression profiles involved in conferring resistance to EGFR TKI therapy in lung cancer cells.

\section{Introduction}

The epidermal growth factor receptor (EGFR) signaling pathway is importantly implicated in tumor cell growth, invasion, angiogenesis and metastasis (1). Molecular aberrations on the EGFR pathway are the most commonly studied predictive biomarkers of response to targeted agents in lung cancer. Non-small cell lung cancers (NSCLCs) harboring somatic gain-of-function mutations in the EGFR tyrosine kinase domain respond well to treatment with the EGFR tyrosine kinase inhibitors (TKIs), gefitinib and erlotinib $(2,3)$. These small molecule TKIs compete with ATP to bind the kinase domain of their targets. Several distinct activating mutations of the EGFR gene have been described in NSCLC, including in-frame deletions in exon 19 (delE746-A750) and a leucine-to-arginine substitution at position 858 (L858R) in exon $21(2,3)$.

All patients who experience a marked improvement with these drugs eventually develop progression of disease subsequent to a median of 12 months due to the acquisition of drug resistance (4). Approximately half of the cases with acquired resistance to EGFR TKIs can be accounted for by a second-site mutation in exon 20 of the EGFR kinase domain, which results in the substitution of methionine for threonine at position 790 (T790M) $(5,6)$. The bulkier methionine residue at position 790 sterically hinders binding of either gefitinib or erlotinib to the ATP-binding pocket. An additional study has indicated that T790M also increases the affinity of EGFR for ATP, thereby out-competing ATP-competitive TKIs and restoring enzymatic activity in their presence (7). However, the changes of gene expression involved in EGFR TKI resistance due to the T790M mutation remain poorly defined. Amplification of $M E T$, a gene encoding a different membrane bound receptor tyrosine kinase, is a separate mechanism of acquired resistance to EGFR TKIs (8). Less frequent forms of acquired resistance include histological transformation to small cell lung cancer $(9,10)$, PIK3CA mutation $(9,11)$ and epithelial to 
mesenchymal transition $(9,12)$. However, the exact frequencies of these mechanisms remain to be established.

Previously, gene expression profiling of human cancers has proved valuable in studies into cancer, providing insights into mechanisms and targets involved in carcinogenesis and drug response in several different types of cancer $(13,14)$. Analysis using mRNA microarrays allows simultaneous assessment of the expression of thousands of genes and this approach provides a valuable means to identify novel molecular targets for therapeutic intervention. Additionally, it may be used to identify genes whose expression is changed in cells with acquired drug resistance by comparing gene expression in drug-resistant cells to that in parental cells that are sensitive to treatment with, for example, EGFR TKIs.

To additionally investigate resistance to EGFR TKIs, the present study has established cell lines that are resistant to either gefitinib or erlotinib. Using mRNA microarrays, genome-wide analysis of gene expression profiles has established a clear division between parental and resistant cells, with altered expression of genes involved in the regulation of cellular proliferation, apoptosis and the cell cycle in the EGFR TKI-resistant cells. The present study may provide key insights into gene expression profiles involved in conferring resistance to EGFR TKI therapy in lung cancer cells.

\section{Materials and methods}

Cell culture and establishment of the gefitinib-and erlotinib-resistant cell lines. The EGFR-mutated NSCLC cell line, PC-9, was used. PC-9 cells are known to contain a deletion in exon 19 (delE746-A750) of EGFR and be highly sensitive to gefitinib and erlotinib (15). Gefitinib- or erlotinib-resistant sublines of PC-9 were established as described previously (16) and these resistant cells were $>100$ times more resistant to gefitinib and erlotinib compared with parental cells. Briefly, parental PC-9 cells were exposed to $10 \mathrm{nmol} / 1$ of gefitinib or erlotinib for $48 \mathrm{~h}$ in medium containing $10 \%$ fetal bovine serum. Subsequently, cells were washed and cultured in drug-free medium until surviving cells were $80 \%$ confluent. These cells were then re-exposed to increasing concentrations of gefitinib or erlotinib. Six months after initial exposure, cells were able to grow in $1 \mu \mathrm{mol} / 1$ of gefitinib or erlotinib. The established drug-resistant cell lines were then maintained in medium containing $1 \mu \mathrm{mol} / 1$ of gefitinib or erlotinib. Gefitinib- or erlotinib-resistant cells are referred to as PC-9G and PC-9E, respectively. PC-9G and PC-9E cells were confirmed to contain the EGFR T790M mutation by DNA sequencing (16). All cells were maintained as monolayer cultures in RPMI 1640 medium supplemented with $10 \%$ fetal bovine serum, $1 \%$ penicillin-streptomycin and $1 \%$ sodium pyruvate at $37^{\circ} \mathrm{C}$ in a humidified incubator in an atmosphere of $5 \% \mathrm{CO}_{2}$. All cell culture materials were obtained from HyClone (GE Healthcare, Logan, UT, USA).

mRNA microarray analysis. Duplicated total RNA sample of each cell lines was prepared using TRIzol ${ }^{\circledR}$ Reagent (Invitrogen; Thermo Fisher Scientific, Inc., Waltham, MA, USA), according to the manufacturer's protocol. The quantity and integrity of extracted RNA was confirmed using a 2100 Bioanalyzer (Agilent Technologies, Inc., Santa Clara, CA, USA) prior to samples being deemed suitable for microarray analysis. Fluorescent complimentary RNA (cRNA) probes were generated and purified using the Agilent's Low RNA Input Linear Amplification kit (Agilent Technologies, Inc.) according to the manufacturer's protocol. Labeled cRNA target was quantified using a NanoDrop-1000 spectrophotometer (NanoDrop Technologies; Thermo Fisher Scientific, Inc.). mRNA microarray hybridization was performed for the samples using the Agilent Whole Human Genome Oligo Microarray (44 K) according to manufacturer's protocol. Briefly, $600 \mathrm{ng}$ Cy3-labeled fragmented cRNA was hybridized overnight to an Agilent Whole Human Genome Oligo Microarray, washed twice, blocked, and scanned using Agilent's microarray scanner.

Data acquisition and statistical analysis. The hybridized images were quantified using the Feature Extraction Software (Agilent Technologies, Inc.). All data normalization and the selection of fold-changed genes were performed using the GeneSpring GX 7.3 (Agilent Technologies, Inc.). The averages of normalized ratios were calculated by dividing the average of normalized signal channel intensity by the average of normalized control channel intensity. Functional annotation of genes was performed according to the Gene Ontology ${ }^{\mathrm{TM}}$ Consortium (http://www.geneontology.org/index.shtml) using the GeneSpring GX 7.3. Gene functional classification was based on searches carried out using the Database for Annotation, Visualization, and Integrated Discovery (DAVID) bioinformatics resources (http://david.abcc.ncifcrf.gov/).

\section{Results}

Distinctive gene expression patterns are revealed by $m R N A$ microarray analysis in EGFR TKI-resistant lung cancer cells with the EGFR T790M mutation. To detect expression changes in the EGFR TKI-resistant cells, an mRNA microarray analysis of $\mathrm{PC}-9 \mathrm{G}$ and $\mathrm{PC}-9 \mathrm{E}$ cells in comparison with drug-naïve parental PC-9 cells was performed. In total, $>20,000$ genes were reliably analyzed following quantile normalization, and those showing fold changes of $>1.5$ were defined as being differentially expressed between the parental and either the PC-9G or PC-9E cells. Among the genes whose expression was significantly altered, the present study focused on those genes whose expression was altered in PC-9G and PC-9E cells (Fig. 1A). A total of 1,617 genes were identified as being differentially expressed in PC-9G and PC-9E cells. Cluster analysis of these differentially expressed genes between PC-9G/PC-9E and parental PC-9 cells identified 451 mRNAs with significantly increased expression in PC-9G and PC-9E compared with in PC-9 cells, and 1,166 mRNAs with significantly reduced expression in PC-9G and PC-9E compared with in PC-9 cells.

Gene ontology analyses of microarray data reveals functional pathways associated with altered $m R N A$ expression in $P C-9 G$ and $P C-9 E$ cells. Genes were functionally categorized with regard to their associated biological process. Gene ontology analysis for the $>1.5$-fold up- or downregulated genes in PC-9G and PC-9E cells was performed using the DAVID tools. According to the DAVID gene ontology program, 1,104 $(68 \%)$ of the 1,617 genes are associated with a known annotated 
Table I. Altered expression of genes involved in cellular proliferation and apoptosis.

Fold change

(vs. PC-9)

\begin{tabular}{|c|c|c|c|c|}
\hline Gene symbol & Description & Genbank & PC-9G & PC-9E \\
\hline \multicolumn{5}{|l|}{ Upregulated } \\
\hline ARHGEF2 & Rho/Rac guanine nucleotide exchange factor (GEF) 2 & NM_004723 & 1.52 & 2.29 \\
\hline$I N P P 5 D$ & Inositol polyphosphate-5-phosphatase, $145 \mathrm{kDa}$ & NM_001017915 & 3.49 & 5.22 \\
\hline \multicolumn{5}{|l|}{ Downregulated } \\
\hline ADORAl & Adenosine A1 receptor & NM_000674 & -2.90 & -5.15 \\
\hline CD24 & CD24 molecule & NM_013230 & -1.91 & -4.39 \\
\hline$C L U$ & Clusterin & NM_001831 & -3.24 & -1.79 \\
\hline EGLN3 & Egl-9 family hypoxia-inducible factor 3 & NM_022073 & -1.59 & -2.18 \\
\hline$F 2 R$ & Coagulation factor II (thrombin) receptor & ВC016059 & -5.15 & -1.68 \\
\hline IL6 & Interleukin 6 (interferon, $\beta 2$ ) & NM_000600 & -1.65 & -1.49 \\
\hline MAGED1 & Melanoma antigen family D, 1 & NM_001005333 & -1.86 & -2.08 \\
\hline NTN1 & Netrin 1 & NM_004822 & -1.63 & -2.68 \\
\hline PHB & Prohibitin & NM_002634 & -2.07 & -1.58 \\
\hline PRKRA & $\begin{array}{l}\text { Protein kinase, interferon-inducible double } \\
\text { stranded RNA dependent activator }\end{array}$ & NM_003690 & -2.74 & -1.43 \\
\hline SMO & Smoothened frizzled class receptor & NM_005631 & -3.72 & -10.07 \\
\hline$T G M 2$ & $\begin{array}{l}\text { Transglutaminase } 2 \text { (C polypeptide, protein- } \\
\text { glutamine-gamma-glutamyltransferase) }\end{array}$ & NM_198951 & -1.81 & -2.02 \\
\hline TNFRSF14 & Tumor necrosis factor receptor superfamily, member 14 & AB208808 & -1.76 & -2.05 \\
\hline TNFRSF8 & Tumor necrosis factor receptor superfamily, member 8 & NM_001243 & -2.78 & -2.27 \\
\hline
\end{tabular}

biological process, $288(64 \%)$ of the 451 upregulated genes and $816(70 \%)$ of the 1,166 downregulated genes. In particular, 96, 115 and 44 genes are associated with the regulation of cellular proliferation, apoptosis and the cell cycle, respectively (Fig. 1B).

Altered expression of genes involved in the regulation of cellular proliferation, apoptosis and the cell cycle. The present study subsequently investigated the genes whose expression was significantly altered in PC-9G and PC-9E cells and that were common in any two or all three ontological clusters: Regulation of cellular proliferation, apoptosis and the cell cycle (Fig. 2A). In total, 40 genes are involved in any two or all three ontological clusters. With the exception of genes involved in all of three ontological clusters, 16 genes are involved in cellular proliferation and apoptosis (Fig. 2B, Table I), six in apoptosis and the cell cycle (Fig. 2B, Table II), and five in the cell cycle and cellular proliferation (Fig. 2B, Table III). A total of 13 genes were identified to be involved in cellular proliferation, apoptosis and the cell cycle (Fig. 2C, Table IV).

Genes listed in Table I-IV were sorted according to their functions, and the genes whose altered expression could promote tumor progression or reduce tumor suppression, favoring tumor growth were selected for further analysis (Table V). Upregulation of the gene encoding amyloid $\beta A 4$ precursor protein-binding family B member 2, which has been reported as an apoptosis inhibitor in aneuploid fibrosarcoma (17), was detected. The gene encoding Rho/Rac guanine nucleotide exchange factor 2 , which is reported as an oncogenic protein in pancreatic cancer (18) and associated with the invasion and metastasis of breast cancer (19), was also upregulated. Previously, interleukin $1 \alpha$ (IL1A) and interleukin $1 \beta$ (IL1B) have been reported as being associated with the growth of lung cancer cells (20). Significant upregulation of the $I L I A$ and $I L 2 B$ genes was observed in the present study, which implied that the tumor microenvironment of resistant cells was altered. Leukemia inhibitory factor (encoded by the $L I F$ gene) has been known to promote tumor progression and radioresistance in nasopharyngeal carcinoma (21). Among the upregulated genes, mouse double minute 2 homolog is a well-known oncogene that can promote tumor formation by targeting tumor suppressor proteins, including $\mathrm{p} 53$, for proteasomal degradation (22). The protein tyrosine phosphatase receptor type $\mathrm{C}$ gene, which is associated with the recurrence of colorectal cancer (23), was also upregulated. The stratifin gene, a gene which was upregulated in the present study, is associated with resistance to chemotherapy and radiotherapy in pancreatic cancer (24) and to tumor invasion in lung cancer (25). The vascular endothelial growth factor A gene, which is associated with angiogenesis in cancer (26) and the migration and invasion of lung cancer (27), was also upregulated.

Among the downregulated genes, the growtharrest-specific 1 gene, which is known to be a tumor suppressor gene (28), was detected. The poly (rC) binding protein 4 gene, which is induced by the p53 tumor suppressor and whose product suppresses cellular proliferation by inducing apoptosis and cell cycle arrest in $\mathrm{G}_{2} / \mathrm{M}$ (29), was also downregulated. Decreased expression of the tumor necrosis factor gene encoding tumor necrosis factor, an inducer of apoptosis (30), was observed. 
Table II. Altered expression of genes involved in apoptosis and the cell cycle.

\begin{tabular}{|c|c|c|c|c|}
\hline \multirow[b]{2}{*}{ Gene symbol } & \multirow[b]{2}{*}{ Description } & \multirow[b]{2}{*}{ Genbank } & \multicolumn{2}{|c|}{$\begin{array}{l}\text { Fold change } \\
\text { (vs. PC-9) }\end{array}$} \\
\hline & & & PC-9G & PC-9E \\
\hline \multicolumn{5}{|l|}{ Upregulated } \\
\hline$A P B B 2$ & $\begin{array}{l}\text { Amyloid } \beta \text { (A4) precursor protein-binding, } \\
\text { family } \mathrm{B}, \text { member } 2\end{array}$ & NM_004307 & 2.09 & 1.55 \\
\hline \multicolumn{5}{|l|}{ Downregulated } \\
\hline$B U B 1 B$ & BUB1 mitotic checkpoint serine/threonine kinase B & NM_001211 & -1.65 & -1.45 \\
\hline FOXCl & Forkhead box C1 & NM_001453 & -1.79 & -2.06 \\
\hline ID3 & $\begin{array}{l}\text { Inhibitor of DNA binding } 3 \text {, dominant negative } \\
\text { helix-loop-helix protein }\end{array}$ & NM_002167 & -1.51 & -1.75 \\
\hline PCBP4 & Poly $(\mathrm{rC})$ binding protein 4 & NM_033010 & -2.24 & -1.54 \\
\hline$S K P 2$ & $\begin{array}{l}\text { S-phase kinase-associated protein 2, E3 ubiquitin } \\
\text { protein ligase }\end{array}$ & NM_032637 & -2.25 & -2.77 \\
\hline
\end{tabular}

Table III. Altered expression of genes involved in the cell cycle and cellular proliferation.

Fold change

(vs. PC-9)

\begin{tabular}{llllr}
\cline { 3 - 4 } Gene symbol & \multicolumn{1}{c}{ Description } & Genbank & PC-9G & PC-9E \\
\hline Upregulated & & & & \\
CDKN2B & Cyclin-dependent kinase inhibitor 2B (p15, inhibits CDK4) & NM_004936 & 1.64 & 2.74 \\
LIF & Leukemia inhibitory factor & NM_002309 & 1.59 & 2.24 \\
$M D M 2$ & MDM2 proto-oncogene, E3 ubiquitin protein ligase & NM_002392 & 1.66 & 2.35 \\
Downregulated & & & & \\
$P I N 1$ & Peptidylprolyl cis/trans isomerase, NIMA-interacting 1 & NM_006221 & -1.87 & -1.47 \\
$P R K C Q$ & Protein kinase C, theta & NM_006257 & -1.78 & -3.08 \\
\hline
\end{tabular}

\section{Discussion}

Gefitinib and erlotinib, commonly considered as the standard treatment for patients with NSCLC who harbor EGFR activating mutations, are two oral drugs that bind the ATP-binding site in the tyrosine kinase domain of the EGFR protein. Somatic mutations occurring in the tyrosine kinase domain of the EGFR gene and responsible for ligand-independent activation of the EGFR pathway have been reported; exon 19 deletions and L858R substitution in exon 21 are the most common, accounting for $90 \%$ of all EGFR activating mutations in NSCLC $(2,3)$. These mutations lead to increased growth signaling, thus conferring susceptibility to treatment with TKIs. Despite the initial clear responses to EGFR TKIs and substantial increase in progression free survival observed in various clinical trials, the majority of patients with NSCLC with an EGFR activating mutation develop acquired resistance subsequent to a median of $\sim 12$ months from treatment initiation (4). Although significant advances have been made, in $\leq 30 \%$ of cases the acquired resistance mechanisms remain unexplained. Therefore, there is an urgent need to identify the underlying mechanisms of resistance in order to develop effective targeted therapies for cancer progression subsequent to EGFR TKI treatment.

The present study established two NSCLC cell lines resistant to the commonly used EGFR TKIs, gefitinib or erlotinib. These cell lines harbor the EGFR T790M mutation, which is the most frequently reported mechanism of acquired resistance to EGFR TKI treatment. The present study aimed to analyze possible gene expression changes associated with EGFR TKI resistance using PC-9G and PC-9E cell lines. Among the genes whose expression was significantly altered, those whose expression was altered in PC-9G and PC-9E cells were focused on, in order to increase the reliability of the results.

It is known that when binding to one of its several ligands, EGFR forms homodimers or heterodimers with other members of the ERBB family receptor tyrosine kinases, and activates downstream pathways, including the phosphatidylinositol 3-kinase/protein kinase B, Raf/mitogen activated protein kinase/extracellular signal-regulated kinases, and janus kinase/signal transducers and activators of transcription signaling pathways, initiating a cascade of signaling events that trigger anti-apoptotic signaling, cellular proliferation, 
Table IV. Altered expression of genes involved in cellular proliferation, apoptosis and also in the cell cycle.

\begin{tabular}{|c|c|c|c|c|}
\hline \multirow[b]{2}{*}{ Gene symbol } & \multirow[b]{2}{*}{ Description } & \multirow[b]{2}{*}{ Genbank } & \multicolumn{2}{|c|}{$\begin{array}{l}\text { Fold change } \\
\text { (vs. PC-9) }\end{array}$} \\
\hline & & & PC-9G & PC-9E \\
\hline \multicolumn{5}{|l|}{ Upregulated } \\
\hline ILIA & Interleukin $1, \alpha$ & NM_000575 & 3.47 & 23.92 \\
\hline$I L 1 B$ & Interleukin $1, \beta$ & NM_000576 & 2.68 & 17.35 \\
\hline PTPRC & Protein tyrosine phosphatase, receptor type, $\mathrm{C}$ & NM_001267798 & 3.61 & 2.25 \\
\hline SFN & Stratifin & NM_006142 & 3.10 & 3.39 \\
\hline$V E G F A$ & Vascular endothelial growth factor A & NM_001025370 & 1.61 & 1.68 \\
\hline \multicolumn{5}{|c|}{ Downregulated } \\
\hline$A N G$ & Angiogenin, ribonuclease, RNase A family, 5 & NM_001145 & -1.50 & -2.70 \\
\hline$E G F R$ & Epidermal growth factor receptor & NM_201283 & -1.79 & -1.72 \\
\hline GAS1 & Growth arrest-specific 1 & NM_002048 & -3.38 & -2.77 \\
\hline$J U N$ & Jun proto-oncogene & NM_002228 & -1.81 & -2.70 \\
\hline$L T B$ & Lymphotoxin $\beta$ (TNF superfamily, member 3) & NM_002341 & -1.90 & -2.70 \\
\hline$P M L$ & Promyelocytic leukemia & NM_033238 & -1.62 & -1.87 \\
\hline TGFB3 & Transforming growth factor, $\beta 3$ & NM_003239 & -2.18 & -2.13 \\
\hline$T N F$ & Tumor necrosis factor & NM_000594 & -4.62 & -2.35 \\
\hline
\end{tabular}

Table V. Genes whose expression was altered towards enhanced tumor progression or reduced tumor suppression.

\begin{tabular}{|c|c|c|c|}
\hline \multirow[b]{2}{*}{ Gene symbol } & \multirow[b]{2}{*}{ Associated process } & \multicolumn{2}{|c|}{$\begin{array}{l}\text { Fold change } \\
\text { (vs. PC-9) }\end{array}$} \\
\hline & & PC-9G & PC-9E \\
\hline \multicolumn{4}{|c|}{ Tumor progression } \\
\hline$A P B B 2$ & Inhibition of tumor cell apoptosis & 2.09 & 1.55 \\
\hline ARHGEF2 & Oncogenic signaling, invasion and metastasis & 1.52 & 2.29 \\
\hline ILIA & Growth of tumor cells & 3.47 & 23.92 \\
\hline$I L 1 B$ & Growth of tumor cells & 2.68 & 17.35 \\
\hline$L I F$ & Tumor progression and radioresistance & 1.59 & 2.24 \\
\hline MDM2 & Tumor formation & 1.66 & 2.35 \\
\hline PTPRC & Cancer recurrence & 3.61 & 2.25 \\
\hline$S F N$ & $\begin{array}{l}\text { Resistance to chemotherapy and } \\
\text { radiotherapy, invasion }\end{array}$ & 3.1 & 3.39 \\
\hline$V E G F A$ & Angiogenesis, migration and invasion & 1.61 & 1.68 \\
\hline \multicolumn{4}{|c|}{ Tumor suppression } \\
\hline GASI & $\begin{array}{l}\text { Inhibition of cellular proliferation and } \\
\text { induction of apoptosis }\end{array}$ & -3.38 & -2.77 \\
\hline PCBP4 & Suppression of cellular proliferation & -2.24 & -1.54 \\
\hline$T N F$ & Apoptosis of tumors cells & -4.62 & -2.35 \\
\hline
\end{tabular}

angiogenesis and tumor invasion and metastasis. Treatment with EGFR TKIs will induce blockage of these pathways. The present data indicated that EGFR TKI-resistant cells are likely to exhibit altered expression of genes that are associated with apoptosis, cellular proliferation and the cell cycle.

Genes, that are associated with at least two of the processes of cellular proliferation, apoptosis, and the cell cycle, and whose expression was significantly altered in EGFR TKI-resistant cells to favor tumor progression, are listed in Table V. As shown in Table V, there was increased expression of genes whose functions are known to promote tumor growth, and decreased expression of genes whose functions are known to suppress tumor growth, in PC-9G and PC-9E cells. It will be necessary to determine the action of these genes in the development of EGFR TKI resistance in NSCLC cells. 

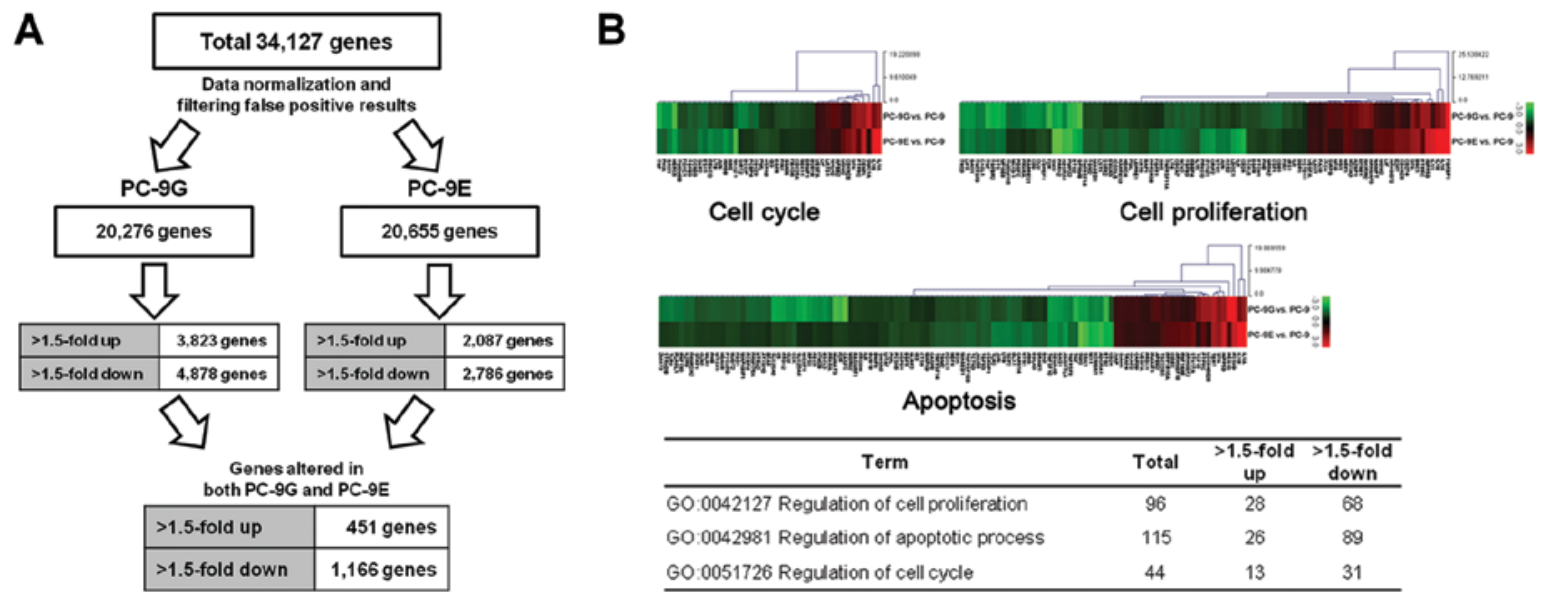

Figure 1. Clustering analysis of mRNA expression profiles of PC-9G and PC-9E cells. (A) Schematic workflow for analyzing gene expression altered in PC-9G and PC-9E cells by mRNA microarray analysis. (B) Gene ontology analysis (GOTERM_BP_ALL) was performed using the DAVID online tool. Functional annotation clustering identified a significantly up- or downregulated cluster of genes in PC-9G and PC-9E cells compared with PC-9 cells. Significantly altered expression of genes associated with the cell cycle, cellular proliferation and apoptosis is expressed by heat map. Transcriptional changes in PC-9G and PC-9E cells are expressed as the fold ratio compared with parental PC-9 cells.

A

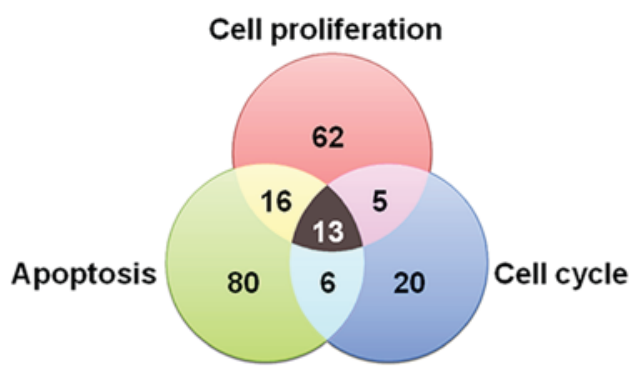

B
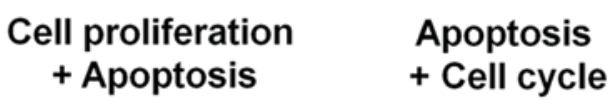

\section{Cell cycle \\ + Cell proliferation}

PC-9E vs. PC-9

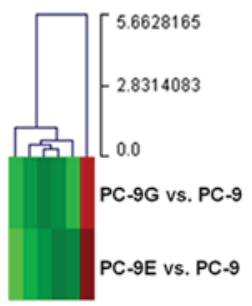

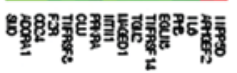

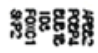
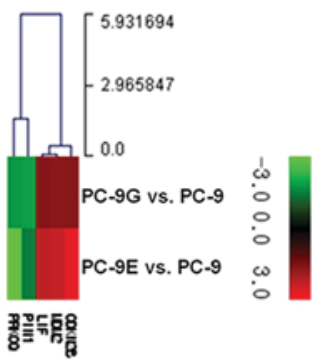

C

Cell proliferation

+ Apoptosis + Cell cycle

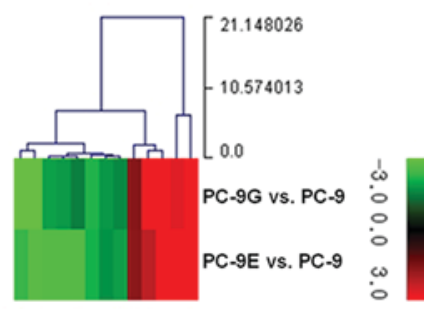

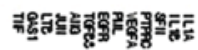

Figure 2. Functional pathways altered with the acquisition of resistance in PC-9G and PC-9E cells. (A) The number of genes common in any two or all three ontological clusters is given at the intersections of the circles. (B) Heat maps for the expression of genes associated with cellular proliferation and apoptosis, apoptosis and the cell cycle, and the cell cycle and cellular proliferation (right) are shown. (C) A heat map for the expression of genes involved in all of cellular proliferation, apoptosis and the cell cycle is presented. Transcriptional changes in resistant cells are expressed as the fold ratio compared with parental PC-9 cells. 
Two previous studies were identified that had used mRNA microarray analysis to examine changes of gene expression in lung cancer cells with acquired resistance to either gefitinib or erlotinib $(12,31)$. However, these studies only examined one cell line resistant to either gefitinib or erlotinib. The present study examined two cell lines with acquired resistance-one to gefitinib and one to erlotinib. Furthermore, genes whose expression was altered in the gefitinib- and the erlotinib-resistant cell line were investigated and the changes of gene expression in terms of major survival pathways were analyzed.

To the best of our knowledge, this is the first study to identify a common mRNA expression profile in cells with acquired resistance to either gefitinib or erlotinib, and can provide key insights into gene expression profiles involved in conferring resistance to EGFR TKI therapy in lung cancer cells. In conclusion, the present study observed distinctive gene expression patterns via mRNA microarray analysis of EGFR TKI-resistant lung cancer cells harboring the EGFR T790M mutation.

\section{Acknowledgements}

The present study was supported by the Korea Institute of Radiological and Medical Sciences Research Fund (grant no. 50452-2014).

\section{References}

1. Hynes NE and Lane HA: ERBB receptors and cancer: The complexity of targeted inhibitors. Nat Rev Cancer 5: 341-344, 2005.

2. Pao W and Chmielecki J: Rational, biologically based treatment of EGFR-mutant non-small-cell lung cancer. Nat Rev Cancer 10 760-774, 2010

3. Cataldo VD, Gibbons DL, Pérez-Soler R and Quintás-Cardama A: Treatment of non-small-cell lung cancer with erlotinib or gefitinib. N Engl J Med 364: 947-955, 2011.

4. Wheeler DL, Dunn EF and Harari PM: Understanding resistance to EGFR inhibitors-impact on future treatment strategies. Nat Rev Clin Oncol 7: 493-507, 2010.

5. Kobayashi S, Boggon TJ, Dayaram T, Jänne PA, Kocher O, Meyerson M, Johnson BE, Eck MJ, Tenen DG and Halmos B: EGFR mutation and resistance of non-small-cell lung cancer to gefitinib. N Engl J Med 352: 786-792, 2005.

6. Pao W, Miller VA, Politi KA, Riely GJ, Somwar R, Zakowski MF, Kris MG and Varmus H: Acquired resistance of lung adenocarcinomas to gefitinib or erlotinib is associated with a second mutation in the EGFR kinase domain. PLoS Med 2: e73, 2005.

7. Yun $\mathrm{CH}$, Mengwasser KE, Toms AV, Woo MS, Greulich H, Wong KK, Meyerson M and Eck MJ: The T790M mutation in EGFR kinase causes drug resistance by increasing the affinity for ATP. Proc Natl Acad Sci USA 105: 2070-2075, 2008.

8. Engelman JA, Zejnullahu K, Mitsudomi T, Song Y, Hyland C, Park JO, Lindeman N, Gale CM, Zhao X, Christensen J, et al: MET amplification leads to gefitinib resistance in lung cancer by activating ERBB3 signaling. Science 316: 1039-1043, 2007.

9. Sequist LV, Waltman BA, Dias-Santagata D, Digumarthy S, Turke AB, Fidias P, Bergethon K, Shaw AT, Gettinger S and Heist RS: Genotypic and histological evolution of lung cancers acquiring resistance to EGFR inhibitors. Sci Transl Med 3: 75ra26, 2011

10. Zakowski MF, Ladanyi $M$ and Kris MG; Memorial Sloan-Kettering Cancer Center Lung Cancer OncoGenome Group: EGFR mutations in small-cell lung cancers in patients who have never smoked. N Engl J Med 355: 213-215, 2006.

11. Yu HA, Arcila ME, Rekhtman N, Sima CS, Zakowski MF, Pao W, Kris MG, Miller VA, Ladanyi M and Riely GJ: Analysis of tumor specimens at the time of acquired resistance to EGFR-TKI therapy in 155 patients with EGFR-mutant lung cancers. Clin Cancer Res 19: 2240-2247, 2013.
12. Suda K, Tomizawa K, Fujii M, Murakami H, Osada H, Maehara Y, Yatabe Y, Sekido Y and Mitsudomi T: Epithelial to mesenchymal transition in an epidermal growth factor receptor-mutant lung cancer cell line with acquired resistance to erlotinib. J Thorac Oncol 6: 1152-1161, 2011.

13. van 't Veer LJ, Dai H, van de Vijver MJ, He YD, Hart AA, Mao M, Peterse HL, van der Kooy K, Marton MJ, Witteveen AT, et al: Gene expression profiling predicts clinical outcome of breast cancer. Nature 415: 530-536, 2002

14. Ruzzo A, Graziano F, Loupakis F, Rulli E, Canestrari E, Santini D, Catalano V, Ficarelli R, Maltese P and Bisonni R: Pharmacogenetic profiling in patients with advanced colorectal cancer treated with first-line FOLFOX-4 chemotherapy. J Clin Oncol 25: 1247-1254, 2007

15. Ono M, Hirata A, Kometani T, Miyagawa M, Ueda S, Kinoshita H, Fujii T and Kuwano M: Sensitivity to gefitinib (Iressa, ZD1839) in non-small cell lung cancer cell lines correlates with dependence on the epidermal growth factor (EGF) receptor/extracellular signal-regulated kinase $1 / 2$ and EGF receptor/Akt pathway for proliferation. Mol Cancer Ther 3: 465-472, 2004.

16. Rho JK, Choi YJ, Lee JK, Ryoo BY, Na II, Yang SH, Lee SS, Kim CH, Yoo YD and Lee JC: The role of MET activation in determining the sensitivity to epidermal growth factor receptor tyrosine kinase inhibitors. Mol Cancer Res 7: 1736-1743, 2009.

17. Lange A, Thon L, Mathieu S and Adam D: The apoptosis inhibitory domain of FE65-like protein 1 regulates both apoptotic and caspase-independent programmed cell death mediated by tumor necrosis factor. Biochem Biophys Res Commun 335: 575-583, 2005.

18. Cullis J, Meiri D, Sandi MJ, Radulovich N, Kent OA, Medrano M, Mokady D, Normand J, Larose J, Marcotte R, et al: The RhoGEF GEF-H1 is required for oncogenic RAS signaling via KSR-1. Cancer Cell 25: 181-195, 2014.

19. Liao YC, Ruan JW, Lua I, Li MH, Chen WL, Wang JR, Kao RH and Chen JH: Overexpressed hPTTG1 promotes breast cancer cell invasion and metastasis by regulating GEF-H1/RhoA signalling. Oncogene 31: 3086-3097, 2012.

20. Engels EA, Wu X, Gu J, Dong Q, Liu J and Spitz MR: Systematic evaluation of genetic variants in the inflammation pathway and risk of lung cancer. Cancer Res 67: 6520-6527, 2007.

21. Liu SC, Tsang NM, Chiang WC, Chang KP, Hsueh C, Liang Y, Juang JL, Chow KP and Chang YS: Leukemia inhibitory factor promotes nasopharyngeal carcinoma progression and radioresistance. J Clin Invest 123: 5269-5283, 2013.

22. Momand J, Zambetti GP, Olson DC, George D and Levine AJ: The mdm-2 oncogene product forms a complex with the p53 protein and inhibits p53-mediated transactivation. Cell 69: 1237-1245, 1992.

23. Chew A, Salama P, Robbshaw A, Klopcic B, Zeps N, Platell C and Lawrance IC: SPARC, FOXP3, CD8 and CD45 correlation with disease recurrence and long-term disease-free survival in colorectal cancer. PLoS One 6: e22047, 2011.

24. Li Z, Dong Z, Myer D, Yip-Schneider M, Liu J, Cui P,

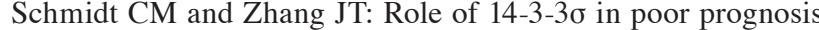
and in radiation and drug resistance of human pancreatic cancers. BMC Cancer 10: 598, 2010.

25. Shiba-Ishii A and Noguchi M: Aberrant stratifin overexpression is regulated by tumor-associated $\mathrm{CpG}$ demethylation in lung adenocarcinoma. Am J Pathol 180: 1653-1662, 2012

26. Carmeliet P: VEGF as a key mediator of angiogenesis in cancer. Oncology 69 (Suppl 3): S4-S10, 2005.

27. Chen CH, Lai JM, Chou TY, Chen CY, Su LJ, Lee YC, Cheng TS, Hong YR, Chou CK, Whang-Peng J, et al: VEGFA upregulates FLJ10540 and modulates migration and invasion of lung cancer via PI3K/AKT pathway. PLoS One 4: e5052, 2009.

28. Domínguez-Monzón G, Benítez JA, Vergara P, Lorenzana R and Segovia J: Gas1 inhibits cell proliferation and induces apoptosis of human primary gliomas in the absence of Shh. Int J Dev Neurosci 27: 305-313, 2009.

29. Zhu J and Chen X: MCG10, a novel p53 target gene that encodes a $\mathrm{KH}$ domain RNA-binding protein, is capable of inducing apoptosis and cell cycle arrest in G(2)-M. Mol. Cell Biol 20: 5602-5618, 2000.

30. Carswell EA, Old LJ, Kassel RL, Green S, Fiore N and Williamson B: An endotoxin-induced serum factor that causes necrosis of tumors. Proc Natl Acad Sci USA 72: 3666-3670, 1975.

31. Terai H, Soejima K, Yasuda H, Sato T, Naoki K, Ikemura S, Arai D, Ohgino K, Ishioka K, Hamamoto J, et al: Long-term exposure to gefitinib induces acquired resistance through DNA methylation changes in the EGFR-mutant PC9 lung cancer cell line. Int J Oncol 46: 430-436, 2015. 